\title{
Social activities and subjective well-being among older persons in Japan
}

\author{
Hirotaka Nakamura ${ }^{1,2}$, Chiyoe Murata*1, Yoshihiko Yamazaki ${ }^{2}$ \\ ${ }^{1}$ National Center for Geriatrics and Gerontology, Obu, Japan \\ ${ }^{2}$ Department of Nursing, Nihon Fukuhsi University, Tokai, Japan
}

Received: December 13, 2018

Accepted: March 3, 2019

Online Published: March 18, 2019

DOI: $10.5430 /$ jer.v5n1p56

URL: https://doi.org/10.5430/jer.v5n1p56

\begin{abstract}
Objectives: In today's aging societies, subjective well-being is an important determinant of quality of life among older persons. The association between better health and better subjective well-being is well known. However, the kinds of social activities associated with subjective well-being are largely unknown. This study aimed to assess such relationships, taking into account the type of social activities involved among community living older persons aged 65 and over.

Method: We used self-administered questionnaire data $(\mathrm{N}=2,652)$ from the Japan Gerontological Evaluation Project (JAGES) 2016. We conducted a poisson regression analyses stratified by age group to elucidate the association between social activities and better subjective well-being.

Results: After adjusting for sex, family composition, household income, number of illnesses and depression, we found that activities to teach skills or passing on experiences to others were significantly related to higher subjective well-being both among the young-old (65-74) and the old-old (75 and over) population.

Conclusion: Altruistic activities such as teaching skills or conveying knowledge to others appear to be related to higher subjective well-being. Promoting social activities has the potential to enhance subjective well-being among the elderly population.
\end{abstract}

Key Words: Subjective well-being, Social activities, Older persons

\section{INTRODUCTION}

Older persons are likely to experience a lower quality of life when they face deteriorating health due to disability, aging, loss of close friends or family, or reduced social activities. In such circumstances, an ability to tolerate psychological challenges occurring as part of the aging process while experiencing psycho-social loss might be important. ${ }^{[1]}$ One study has focused on psycho-social factors affecting mind and body. ${ }^{[2]}$ Several studies reported that positive emotions increase the volume of the inner prefrontal cortex, and enhance health through accelerating autonomic nervous functions and endocrine suppression functions. ${ }^{[3,4]}$ Subjective well-being is one of the indicators of such positive emotions.

Work and community are considered as factors related to subjective well-being, and continuous contact with other people in society has also been reported to have positive effects on the health of older persons. ${ }^{[5-8]}$ In a study in Japan, ${ }^{[9]}$ the type of life style, depression, and better physical functions also emerged as factors associated with the likelihood or otherwise of a higher subjective well-being.

Some studies have shown that happiness, a component of

*Correspondence: Chiyoe Murata; Email: cmurata@ncgg.go.jp; Address: National Center for Geriatrics and Gerontology, 7-430 Morioka-cho, Obu, Aichi 474-8511, Japan. 
subjective well-being, is influenced by culture, religion, and family values. ${ }^{[10,11]}$ One's personality has also been found to be positively associated with the extent of life satisfaction or subjective well-being one experiences. ${ }^{[12,13]}$ According to a review of 19 national and cross-national studies, health, income, employment, one's attitudes and beliefs, personal relations, family, the economic, social and political environment, community involvement, and social activities were positively associated with subjective well-being. ${ }^{[14,15]}$ On the other hand, McNeil et al. ${ }^{[15]}$ reported inconsistent results in terms of associations between types of social activities and subjective well-being. As far as we know, no studies have analyzed the association between social activities and subjective well-being in detail, taking into account the type of social activities involved. This study aimed to determine the kinds of social activities associated with better subjective well-being among older persons.

\section{MethodS}

\subsection{Data}

This study was undertaken as part of the Japan Gerontological Evaluation Study (JAGES) project. The aim of the JAGES is to identify enabling factors that bring about a long and healthy life among elderly people, and its study protocols are described in detail in a recent article on the project. ${ }^{[16]}$ We used self-administered questionnaire data obtained from 4,074 randomly sampled older persons living in a municipality in Japan, during October and November 2016. The response rate was $73.0 \%$, yielding data for 2,974 persons. We used data from 2,652 persons in which there were no missing variables related to subjective well-being and social activities for this study.

\subsection{Subjective well-being}

We used subjective happiness as a vicarious term to indicate subjective well-being in this study, since happiness is considered an important component of one's subjective wellbeing. ${ }^{[12,13]}$ Subjective happiness was measured using the following question, "How happy are you now?" with 11 answering options from 0 (very unhappy) to 10 (very happy). We dichotomized answers with a cut-off point of 8; higher subjective well-being (coded 1) versus lower subjective wellbeing (coded 0$)$.

\subsection{Explanatory variables}

We used social activity items as described in the Japanese General Social Survey (JGSS), ${ }^{[17]}$ namely, "Sports group or club", "Volunteer group", "Leisure activity group", "Senior citizen club", "Neighborhood association or residents" association", "Study or cultural group", "Nursing care prevention or health-building", and "Teaching skills or passing on experiences to others". "Nursing care prevention or healthbuilding" refers to activities aimed at preventing functional loss or preserving functional ability among older persons, ${ }^{[18]}$ and usually comprises physical or intellectual activities such as light exercise or performing drills to preserve cognitive activity. Also, we added "Paid work" as a social activity item, since paid job has been identified as the primary social activity engaged in by older persons. ${ }^{[19]}$ In total, we used 9 activity items for assessment. We asked, "How often do you participate in each of the following activities?" The answers were dichotomized for each social activity: once a month or more (coded 1), and less than once a month (coded 0$)$.

\subsection{Covariates}

According to a 2007 survey on happiness in Japan, ${ }^{[9]}$ the primary reasons for feeling happy were identified as being in good health, having economic stability, and having good family relations. In studies involving other countries, physical as well as mental health factors were also reported as associated with subjective well-being. ${ }^{[1,10]}$ Thus, to adjust for these factors, we treated the following items as covariates in our model: family composition, living alone (1) versus living with someone else (0); annual household income, less than 2 million yen, equivalent of about 170 US dollars (1) versus 2 million yen and above (0); the 15 item Geriatric Depression Scale (GDS-15), 5 points and above as being depressed (1) versus not being depressed ( 0 ), and: the number of illnesses under treatment. Illnesses were ascertained through asking whether respondents were currently receiving treatment for any of the following: cancer, heart disease, stroke, hypertension, diabetes, obesity, hyperlipidemia, osteoporosis, arthritis, trauma, respiratory illness, gastrointestinal illness, liver disease, mental illness, visual/hearing impairment, dysphagia, or incontinence. Income was defined as pre-tax annual household income including regular salary, pensions, social security, and any form of temporary earnings occurring during one year. Since household income differs between one-person households and multi-person households, we adjusted income for family size by dividing total household income by the square root of the number of people in the household, as done in other JAGES project studies. ${ }^{[16]}$

\subsection{Analytical methods}

Since what engagement in social activity entails might differ by age, we adjusted for age, stratifying our sample into two age groups: young-old (aged 65-74) and old-old (75 and over). We conducted Poisson regression analysis to avoid overestimation of the association, as the percentage of those in the groups with higher subjective well-being surpassed 10\%. ${ }^{[20]}$ We used SPSS 24.0J (SPSS, Chicago, IL, USA) for statistical analysis. A $p$-value of less than .05 was considered 
statistically significant for all the analyses.

\subsection{Ethical considerations}

The study protocol and informed consent procedures were approved by the Ethics Committee in Research on Human Subjects at the National Center for Geriatrics and Gerontology (Reg. No. 992.)

\section{RESULTS}

Table 1 shows the distribution of subjective well-being, which was similar to the results of studies conducted in Denmark and UK, showing normal distribution with 8 points as the highest score. ${ }^{[9]}$ In Table 1, the highest score was 8 with 733 answers $(27.8 \%)$, followed by 7 with 455 answers $(17.5 \%)$ and 5 with 400 answers (13.8\%). Table 2 shows baseline characteristics of participants by age group and subjective well-being. As shown in Table 3, among persons with higher subjective well-being, "Teaching skills or passing on experiences to others" was the highest scoring item among both the young-old (69.2\%) and the old-old (67.9\%) age groups. Among the young-old group, "Study or cultural group" $(61.5 \%)$ and "Nursing care prevention or health-building" $(60.2 \%)$ were the next highest scoring items, whereas among the old-old group: "Paid work" (66.4\%) and "Nursing care prevention or health-building" (64.7\%) were then next highest scoring items.

Table 1. Distribution of subjective well-being among participants

\begin{tabular}{lll}
\hline Subjective well-being score & $\mathbf{N}$ & $\mathbf{\%}$ \\
\hline missing & 204 & 7.1 \\
0 & 3 & 0.0 \\
1 & 4 & 0.2 \\
2 & 10 & 0.3 \\
3 & 35 & 1.2 \\
4 & 38 & 1.2 \\
5 & 400 & 13.8 \\
6 & 268 & 9.7 \\
7 & 455 & 17.5 \\
8 & 733 & 27.8 \\
9 & 323 & 10.8 \\
10 & 383 & 11.6 \\
\hline
\end{tabular}

Table 2. Baseline characteristics by age group and subjective well-being

\begin{tabular}{|c|c|c|c|c|c|}
\hline & & \multicolumn{2}{|c|}{ Young-old $(n=1,636)$} & \multicolumn{2}{|c|}{ Old-old $(n=1,016)$} \\
\hline & & $\begin{array}{l}\text { High Subjective } \\
\text { well-being } \\
\mathrm{n}=873\end{array}$ & $\begin{array}{l}\text { Low subjective } \\
\text { well-being } \\
\mathrm{n}=763\end{array}$ & $\begin{array}{l}\text { High subjective } \\
\text { well-being } \\
\mathrm{n}=566\end{array}$ & $\begin{array}{l}\text { Low subjective } \\
\text { well-being } \\
n=450\end{array}$ \\
\hline \multicolumn{6}{|l|}{ Sex } \\
\hline Women & $(\%)$ & 56.8 & 46 & 53.4 & 46.9 \\
\hline Living alone & $(\%)$ & 7.0 & 12.5 & 13.1 & 14.4 \\
\hline $\begin{array}{l}\text { Equivalized annual household } \\
\text { income } \\
\text { (Less than } 2 \text { million yen) }\end{array}$ & $(\%)$ & 29.1 & 40.4 & 37.5 & 40.9 \\
\hline \multicolumn{6}{|l|}{ Health status } \\
\hline Depression (GDS-15) & $0-15$ & 3.52 (2.94) & $6.11(1.26)$ & $1.40(1.77)$ & $3.90(3.24)$ \\
\hline
\end{tabular}

To assess factors associated with subjective well-being while adjusting for possible confounders, we conducted Poisson regression analysis (see Table 4). After adjusting for sex, family composition, household income, illnesses under treatment and depression, "Teaching skills or passing on experiences to others" was found to be significantly related to subjective well-being both among young-old and the old-old persons, with prevalence ratios of 1.19 (1.05-1.35) and 1.22 (1.03-1.45), respectively. In addition, among the old-old, "Volunteer group", "Senior citizen club" and "Nursing care prevention or health-building" were associated with better subjective well-being, with prevalence ratios of 1.21 (1.06$1.39), 1.17$ (1.02-1.34), and 1.22 (1.03-1.45).

\section{Discussion}

In both age groups, "Teaching skills or passing on experiences to others" was significantly related to subjective wellbeing, even after adjusting for depression. Studies outside Japan have found seven factors related to subjective wellbeing, namely, family relationships, financial situation, work, 
community, friends, health, and personal freedom or val- family relationships, and financial stability have been identiues. $^{[21]}$ In Japan, similar factors, such as good health, good fied. ${ }^{[9]}$

Table 3. Proportion of high subjective well-being by age group and social activities

\begin{tabular}{|c|c|c|c|c|c|}
\hline \multicolumn{3}{|c|}{ Young-old } & \multicolumn{3}{|c|}{ Old-old } \\
\hline & $\mathrm{n}$ & $\%$ & & $\mathrm{n}$ & $\%$ \\
\hline $\begin{array}{l}\text { Teaching skills or passing } \\
\text { on experiences to others }\end{array}$ & 72 & 69.2 & $\begin{array}{l}\text { Teaching skills or passing on } \\
\text { experiences to others }\end{array}$ & 38 & 67.9 \\
\hline Study or cultural group & 80 & 61.5 & Paid work & 79 & 66.4 \\
\hline $\begin{array}{l}\text { Nursing care prevention or } \\
\text { health-building }\end{array}$ & 65 & 60.2 & $\begin{array}{l}\text { Nursing care prevention or } \\
\text { health-building }\end{array}$ & 55 & 64.7 \\
\hline Volunteer group & 296 & 58.0 & Study or cultural group & 49 & 63.6 \\
\hline $\begin{array}{l}\text { Neighborhood association } \\
\text { or residents’ association }\end{array}$ & 70 & 57.9 & Senior citizen club & 75 & 63.6 \\
\hline Leisure activity group & 307 & 57.0 & Volunteer group & 151 & 62.7 \\
\hline Sports group or club & 133 & 56.6 & Sports group or club & 72 & 61.5 \\
\hline Senior citizen club & 43 & 55.8 & Leisure activity group & 177 & 58.8 \\
\hline Paid work & 281 & 52.9 & $\begin{array}{l}\text { Neighborhood association or } \\
\text { residents' association }\end{array}$ & 36 & 57.1 \\
\hline
\end{tabular}

Note. Percentages in the table are the proportion of persons with high subjective well-being in each activity.

In terms of "Teaching skills or passing on experiences to others," it has been reported that being able to convey their experiences to the next generation is important for older persons. ${ }^{[23]}$ From a psychological perspective, studies have indicated that when elderly people were able to use their remaining functions and could integrate their life experience meaningfully when looking to the future through accepting their past and present situation, there was a positive association with fewer symptoms of dementia, ${ }^{[24,25]}$ and positive feelings have been shown to have positive psychological effects on subjective well-being, reducing the risk of dementia. ${ }^{[26]}$

However, there were minor differences between the age groups. Among the old-old group, "Senior citizen club" "Volunteer group" or "Nursing care prevention or health-building" were related to higher subjective well-being. Overall, when people become older, they are more likely to experience stress due to the loss of loved ones or of functional ability. We considered that altruistic activities such as volunteering or passing on experiences to others might have provided stress-alleviating effects that led to heightened subjective well-being among the elderly people in our study. This consideration is in accordance with studies that have found that these kinds of activities contribute to improvement in bodily functions, ${ }^{[22]}$ and in feelings of happiness. ${ }^{[29-31]}$

On the other hand, we did not find any obvious relationship between income and happiness, as reported in studies showing a positive relationship between higher income and happiness. ${ }^{[27,28]}$ It is possible that it is not so much the monetary reward per se but rather the social role maintained through engagement in paid work or volunteering that influences the finding of higher well-being among elderly people, through heightened self-esteem. A review of studies on social support and health reported similar findings. ${ }^{[31]}$ More studies on the social activities of older persons from a psychological perspective might be warranted.

There are several limitations to this study, to be addressed in future studies. First, as this study was cross-sectional, causal links between altruistic activities, such as conveying skills or experiences to others or volunteering, and subjective well-being, could not be established. Caution is required in 
interpreting these results. Second, this study used secondary data from only one small city in Japan, taken from a large national project. Since subjective well-being is influenced by culture, ${ }^{[10,11]}$ it is likely that the generalizability of these results is limited. Nevertheless, this study's findings showed the potential for altruistic activities to have positive effects on the subjective well-being of elderly persons.

Table 4. Relationship between subjective well-being and social activities by age group

\begin{tabular}{|c|c|c|}
\hline & Young-old $(n=1,636)$ & Old-old $(n=1,016)$ \\
\hline \multirow{2}{*}{ Sports group or club } & 1.08 & 1.10 \\
\hline & $(0.97-1.21)$ & $(0.94-1.28)$ \\
\hline \multirow{2}{*}{ Volunteer group } & 1.06 & $1.21^{* *}$ \\
\hline & $(0.88-1.17)$ & (1.06-1.39) \\
\hline \multirow{2}{*}{ Leisure activity group } & 0.94 & 1.06 \\
\hline & $(0.77-1.15)$ & $(0.98-1.15)$ \\
\hline \multirow{2}{*}{ Senior citizen club } & 1.05 & $1.17^{*}$ \\
\hline & $(0.90-1.23)$ & $(1.02-1.34)$ \\
\hline \multirow{2}{*}{ Neighborhood association or residents' association } & 0.99 & 1.07 \\
\hline & $(0.86-1.14)$ & $(0.85-1.33)$ \\
\hline \multirow{2}{*}{ Study or cultural group } & 1.10 & 1.07 \\
\hline & $(0.96-1.30)$ & $(0.92-1.26)$ \\
\hline \multirow{2}{*}{ Nursing care prevention or health-building } & 1.03 & $1.21 *$ \\
\hline & $(0.91-1.17)$ & $(1.03-1.42)$ \\
\hline \multirow{2}{*}{ Teaching skills or passing on experiences to others } & $1.19 * *$ & $1.22 *$ \\
\hline & $(1.05-1.35)$ & $(1.03-1.45)$ \\
\hline \multirow{2}{*}{ Paid work } & 1.08 & 1.06 \\
\hline & (0.98-1.19) & $(0.90-1.24)$ \\
\hline
\end{tabular}

Note. $* * p<.01 * p<.05$. We adjusted for sex, family composition, household income, number of illnesses under treatment, and depression using Poisson regression models. Figures in the table are prevalence ratios (95\% confidence intervals).

\section{Conclusion}

In this study, altruistic activities such as conveying skills to others were found to be significantly associated with subjective well-being, even after adjusting for income, family composition, illnesses and depression, in older populations. Among the old-old population, volunteering was also significantly associated with higher subjective well-being.

As this is a preliminary analysis, further examination of the psychological effects of social activities on the older population using a longitudinal study is needed. Such knowledge can be useful for practitioners and policy makers to promote social activities among the elderly population. Based on current studies, the Japanese government has started promoting social activities among older persons; however, most persons at risk, especially single men, do not engage in any kind of activities. Thus, further studies on the association of subjective well-being with social activities are warranted.

\section{ACKNOWLEDGEMENTS}

We would like to thank the study participants, and Dr. Katsunori Kondo from Chiba University and the National Center for Geriatrics and Gerontology for his valuable comments and providing data for this study. This study is a part of the JAGES project, which receives funds from the JSPS (Japan Society for the Promotion of Science) under the following grants (kakenhi) (JP15H01972, JP15H04781, JP15H05059, JP15K03417, JP15K03982，JP15K16181，JP15K17232, JP15K18174, JP15K19241, JP15K21266, JP15KT0007, JP15KT0097, JP16H05556, JP16K09122, JP16K00913, 
JP16K02025, JP16K12964, JP16K13443, JP16K16295, search and development grants from Longevity Sciences of JP16K16595, JP16K16633, JP16K17256, JP16K19247, the AMED (Japan Agency for Medical Research and DeJP16K19267, JP16K21461, JP16K21465, JP16KT0014, velopment) (16dk0110017h0002, 16ls0110002h0001), and JP25253052，JP25713027，JP26285138， JP26460828, JP26780328, JP17K04306), Health Labor Sciences research grants (H26-Choju-Ippan-006, H27-Ninchisyou-Ippan-001 H28- Choju-Ippan-002, H28- Ninchisyou-Ippan-002), reresearch funding from Longevity Sciences of the National Center for Geriatrics and Gerontology (24-17, 24-23, 30-31), and the Japan Foundation for Aging and Health.

\section{REFERENCES}

[1] Erikson EH. "Identity crisis" in perspective. In: EH Erikson, Life history and the historical moment. New York, NY: Norton, 1970.

[2] Izawa $S$, Sugaya $N$, Kimura $K$, et al. An increase in salivary interleukin-6 level following acute psychosocial stress and its biological correlates in healthy young adults. Biol Psychol. 2013; 94(2): 249-254. PMid: 23831278. https://doi.org/10.1016/j.biop sycho.2013.06.006

[3] Kanai R, Bahrami B, Duchaine B, et al. Brain structure links loneliness to social perception. Curr Biol. 2012; 22(20): 1975-9. https://doi.org/10.1016/j.cub.2012.08.045

[4] Roy M, Shohamy D, Wager TD. Ventromedial prefrontal-subcortical systems and the generation of affective meaning. Trends Cogn Sci. 2012; 16(3): 147-56. https://doi.org/10.1016/j.tics. 201 2.01 .005

[5] Matsunaga M, Kawamichi H, Koike T, et al. Structural and functional associations of the rostral anterior cingulate cortex with subjective happiness. Neuroimage. 2016; 134: 132-41. https ://doi.org/10 $.1016 / j$. neuroimage .2016 .04 .020

[6] Emmons RA, McCullough ME. Counting blessings versus burdens: an experimental investigation of gratitude and subjective well-being in daily life. J Pers Soc Psychol. 2003; 84: 377-89. PMid: 12585811. https://doi.org/10.1037/0022-3514.84.2.377

[7] Martinez-Marti ML, Avia MD, Hernandez-Lloreda MJ. The effects of counting blessings on subjective well-being: a gratitude intervention in a Spanish sample. Span J Psychol. 2010; 13: 886-96. PMid: 20977036. https://doi.org/10.1017/S1138741600002535

[8] Cheng ST, Tsui PK, Lam JH. Improving mental health in health care practitioners: randomized controlled trial of a gratitude intervention. J Consult Clin Psychol. 2015; 83: 177-86. https: //dx.doi.org/10.1002/gps.1314

[9] Sodekawa Y, Tanabe T. Study on Happiness; Subjective Well-Being and Economic Growth 2007 (in Japanese). Economic and Social Research Institute (ESRI). Available from: https://ideas.repe c.org/p/esj/esridp/182.html

[10] Chan YK, Lee RPL. Network Size, Social Support and Happiness in Later Life: A Comparative Study of Beijing and Hong Kong. Journal of Happiness Studies: An Interdisciplinary Forum on Subjective Well-Being. 2006; 7(1): 87-112. https ://doi.org/10.1007/s1 0902-005-1915-1

[11] Cheng ST, Li KK, Leung EMF, et al. Social Exchanges and Subjective Well-being: Do Sources of Positive and Negative Exchanges Matter? The Journals of Gerontology: Series B. 2011; 66B(6): 70818. http://dx.doi.org/10.1093/geronb/gbr061

[12] Nanthamongkolchai S, Tuntichaivanit C, Munsawaengsub C, et al. Factors influencing life happiness among elderly females in Rayong Province, Thailand. Journal of the Medical Association of Thailand Chotmaihet Thangphaet. 2009; 92(7): s8-s12.

[13] Dowlati Y, Herrmann N, Swardfager W, et al. A meta-analysis of cytokines in major depression. Biol Psychiatry. 2010; 67, 446-457. http://dx.doi.org/10.1016/j.biopsych.2009.09.03)

[14] Dolan P, Peasgood T, White M. Do we really know what makes us happy? A review of the economic literature on the factors associated with subjective well-being. Journal of Economic Psychology. 2008; 29(1): 94-122. https://doi.org/10.1016/j.joep. 200 7.09.001

[15] McNeil KJ, Stones MJ, Kozma A. Subjective well-being in later life: Issues concerning measurement and prediction. Social Indicators Research. 1986; 18(1): 35-70. https://doi.org/10.1007/BF00 302532

[16] Kondo K. Progress in Aging Epidemiology in Japan: The JAGES Project. J Epidemiol. 2016; 26(7): 331-336. https : //doi .org/10 .2188/jea. JE20160093

[17] Japanese General Social Surveys. Available from: http://jgss.daishodai.ac.jp/surveys/sur_quest/J GSS2002_Questionnaire_SelfAdministered.pdf (2018.7)

[18] Ministry of Health, Labor and Welfare. Preventing long-termcare. Available from: https://www.mhlw.go.jp/stf/seisakunits uite/bunya/hukushi_kaigo/kaigo_koureisha/yobou/ind ex.html (2019.2)

[19] Yoshinori Fujiwara. Seamless social participation and intergenerational relationships among older adults: A proposal for multilayered support according to one's life course. Geriatric Medicine. 2017; 55(2): 155-8. PMid: 2017146116.

[20] Lee J, Tan CS, Chia KS. A practical guide for multivariate analysis of dichotomous outcomes. Ann Acad Med Singapore. 2009; 38: 714-9. PMid: 19736577.

[21] Layard R. Happiness: Lessons from a New Science. New York: Penguin Press, 2005. 62p.

[22] Borgonovi F. Doing well by doing good. The relationship between formal volunteering and self-reported health and happiness. Social Science \& Medicine. 2008; 66: 2321-34. PMid: 18321629. https://doi.org/10.1016/j. socscimed.2008.01.011

[23] Nishida S, Kondo S, Takagi M, et al. Effectiveness of an OccupationBased Home-Visit Program for Clients with Dementia and Caregivers: A Pilot Study. Asian Journal of Occupational Therapy. 2017; 13: 7-12. https://doi.org/10.11596/asiajot.13.7

[24] Tabourne CES. The Effects of a Life Review Program on Disorientation, Social Interaction and Self-Esteem of Nursing Home Residents. The International Journal of Aging and Human Development. 1995; 41: 251-66. https://doi .org/10.2190/EG53-878E-MGR $\mathrm{K}-\mathrm{BCPP}$

[25] Namazi KH, Haynes SR. Sensory stimuli reminiscence for patients with Alzheimer's disease: Relevance and implications. Clinical Gerontologist: The Journal of Aging and Mental Health. 1994; 14: 29-46. https://doi.org/10.1300/J018v14n04_04

Published by Sciedu Press 
[26] Murata C, Takeda T, Suzuki K, et al. Positive affect and incident dementia among the old. Journal of Epidemiological Research. 2016; 2(1): 118-24. https://doi.org/10.5430/jer.v2n1p118

[27] Easterlin RA. Does Economic Growth Improve the Human Lot? Some Empirical Evidence. In: David PA, Reder MW, editors. Nations and Households in Economic Growth: Academic Press. 1974; 89-125. https://doi.org/10.1016/B978-0-12-205050-3.50008-7

[28] Subramanian SV, Blakely T, Kawachi I. Income Inequality as a Public Health Concern: Where Do We Stand? Commentary on "Is Exposure to Income Inequality a Public Health Concern?". Health Services Research. 2003; 38: 153-67. https://doi.org/10.1111/1475 $-6773.00110$
[29] Kolarcik P, Geckova AM, Reijneveld SA, et al. The mediating effect of discrimination, social support and hopelessness on self-rated health of Roma adolescents in Slovakia. Int J Equity Health. 2015; 14: 137. https://doi .org/10.1186/s12939-015-0270-z

[30] Fujiwara Y, Shinkai S, Watanabe S, et al. Longitudinal changes in higher-level functional capacity of an older population living in a Japanese urban community. Arch Gerontol Geritater. 2003; 3: 63-68. PMid: 12849088. https://doi.org/10.1016/S0167-4943(02 ) 00081-X

[31] Graven LJ, Grant J. The impact of social support on depressive symptoms in individuals with heart failure: update and review. $\mathrm{J}$ Cardiovasc Nurs. 2013; 28: 429-43. https://doi.org/10.1097/ JCN. Ob013e3182578b 